\title{
THERMAL PROPERTIES OF 3D-PRINTED SAND MOLDS
}

\author{
Mahsa Saeidpour (1), Roger Svenningsson, Ulf Gotthardsson, and Sten Farre \\ RISE Research Institutes of Sweden, Materials and production, Manufacturing processes, Jönköping, Sweden
}

Copyright $(\subset) 2021$ The Author(s)

https://doi.org/10.1007/s40962-021-00583-x

\begin{abstract}
Specific heat capacity $\left(C_{p}\right)$, density $(\rho)$, and thermal conductivity $(\lambda)$ of phenolic-bonded $3 D$-printed sand (3DPS) molds have been determined in the temperature range of $20-1400{ }^{\circ} \mathrm{C}$ using differential scanning calorimeter (DSC), dilatometer, and hot wire method. The results have been used to simulate the thermal gradient in a sand mold

properties cannot explain the thermal gradient in 3DPS molds and this manufacturing process affects the thermal properties of the mold compared to traditional mold making. It is necessary to collect data for a variety of $3 D$ printed sand molds to ensure accurate modeling simulation in the foundry industry.
\end{abstract} during casting aluminum using a commercial simulation software. The simulated results have been compared with laboratory-measured results and simulated results using the software's database for conventional mold making. Our results show that available database for sand thermal
Keywords: 3D-printed sand molds, thermal properties, casting, sand casting, phenolic binder, additive manufacturing technology (AM)

\section{Introduction}

Sand casting is an economical metal-forming process that has been used to manufacture metal objects since more than 3000 years. Relative to other forms of casting methods, making components in a sand mold provides a wide range of sizes, complexity, and types of metal alloys. The additive manufacturing (AM) technology, also referred to as $3 \mathrm{D}$ printing, for manufacturing the sand molds, gives foundries new possibilities to design more complex geometries and manufacture molds without using physical patterns. The 3D-printed mold technology has a potential to change the future of mold production in foundries and take over or partially replace the conventional molding methods. ${ }^{1}$ Newly conducted researches illustrate how this technology provides novel opportunity for foundry industries such as reducing shrinkage by allowing casting in optimal orientation ${ }^{2}$ and improving mechanical properties using topology optimization approach. ${ }^{3}$

Sand printers use binder jetting technology to ink jet a binder resin into a catalyst-mixed sand. First a layer of sand

Received: 31 August 2020 / Accepted: 09 February 2021 / Published online: 10 April 2021 mixed with activator is placed in the working box, and then the printer head which is connected to a program places the resin binder on specific places. When the binder meets the activated sand, a polymerization reaction occurs which bonds the particles together. After printing a layer, a new layer of sand is re-coated over the previous layers and the process repeats until the mold and/or cores are completed. Different types of sand and binders may be used in this process. ${ }^{4}$ The most common is silica sand and phenolic or furan-based resins. This special production process may give the 3D-printed sand (3DPS) molds different properties than other conventional sand mold production methods.

Thermal properties of molds and cores influence the metal solidification process, the microstructure of the casting, and the unwanted formation of different casting defects. Generally, the knowledge and databases regarding the thermal properties of sand molds and methods to measure these properties are relatively limited. This affects the results accuracy from the simulations. ${ }^{5,6}$ The process in which a 3DPS mold is printed causes variation of sand thermomechanical properties from conventional sand mold. The recent growing popularity of 3DPS has created a need to evaluate these properties and to update the simulation databases for 3DPS molds. ${ }^{7}$ 
A few studies have attempt to evaluate the thermal properties of 3DPS molds, for instance, Judith et al. ${ }^{8}$ used a method based on temperature measurements inside 3Dprinted spherical-shaped core sand specimens and used a special application of Fourier thermal analysis to calculate the thermal properties and the decomposition characteristics of the 3D-printed cores. In this study, they evaluated the rate of heat absorption in 3DPS molds with different binder systems during casting iron and aluminum. In another study ${ }^{1}$ the specific heat and density of 3DPS molds and effect of binder amounts were investigated in the temperature range of $20-300{ }^{\circ} \mathrm{C}$. The density of 3DPS molds is around $1.3 \mathrm{~g} / \mathrm{cm}^{3}$. Martinez et al. ${ }^{9}$ compared the thermal properties obtained via analytical one-dimensional solution to the results measured with the transient plane source (TPS) technique for 3DPS molds. They concluded that the thermal conductivity, diffusivity and heat capacity increase with increasing binder content.

In this paper, we first evaluate the thermal properties of 3DPS molds in the broad temperature range of $20-1400{ }^{\circ} \mathrm{C}$ using differential scanning calorimeter (DSC), dilatometer, and hot wire method. The results are used to improve the material databases in commercial simulation code, NovaFlow casting simulation software. The accuracy of the measured thermal properties data was evaluated using casting experiment in laboratory. The evaluated data in this paper can improve applications and extend the potential of sand 3D mold and core printing technology.

\section{Experimental Procedure}

\section{Measurement Set-up Experiment}

The temperature gradient during casting was measured using a mold consisting of three cake-shape thirds made of 3D-printed sand with different binder systems. Figure 1 shows an illustration of a mold with cake-shape thirds. In this specific set-up, each cylinder consists of 3 parts (slices) made of different 3D-printed sand. The melt is poured in the cylindrical hole in the middle of the mold. The diameter of the hole is $98 \mathrm{~mm}$, and the diameter of the mold is $430 \mathrm{~mm}$. the height of the cylinder is $300 \mathrm{~mm}$.

Four small cavities were designed in each sand slice to place thermocouples in the sand. The thermocouples were placed in the same depth $(150 \mathrm{~mm})$ in the cake shapes with the distance from the center of the melt of $65,90,115$, and $200 \mathrm{~mm}$.

The thermocouples used in the sand were type $K$ thermocouples, and the temperature was measured each second. In addition to this, an extra $K$-type thermocouple was placed in the middle of cylinder to monitor the melt temperature. Each mold was equipped with a casting cup, where the metal was poured.

The casting cup was designed to protect the thermocouples set-up from being destroyed by the metal and to control the metal flow inside the cylinder. A filter was placed on the top of cylinder to control the metal flow during casting. The filter was a 20-ppi filter from Foseco with diameter of $50 \mathrm{~mm}$ and thickness of $22 \mathrm{~mm}$.

A summary of casting experiments in this study is shown in Table 1. This special set-up gave us the possibility to measure the temperature gradient in 3 different 3DPS (with different binder types) in one single casting. This improves the accuracy and simplifies the comparison between the temperature readings in the cake shapes. The results are the average of two castings run.

The 3DPS were produced using commercial 3D sand printers from two companies in Europe. In these 3D printers high-purity silica sand $\left(98 \% \mathrm{SiO}_{2}\right)$ with average particle size of $0.19 \mathrm{~mm}$ and $66 \mathrm{GFN}$ was used. The 3Dprinted sand molds in this study were phenolic resolebonded sand mold, using printer from company 1 (P1S),
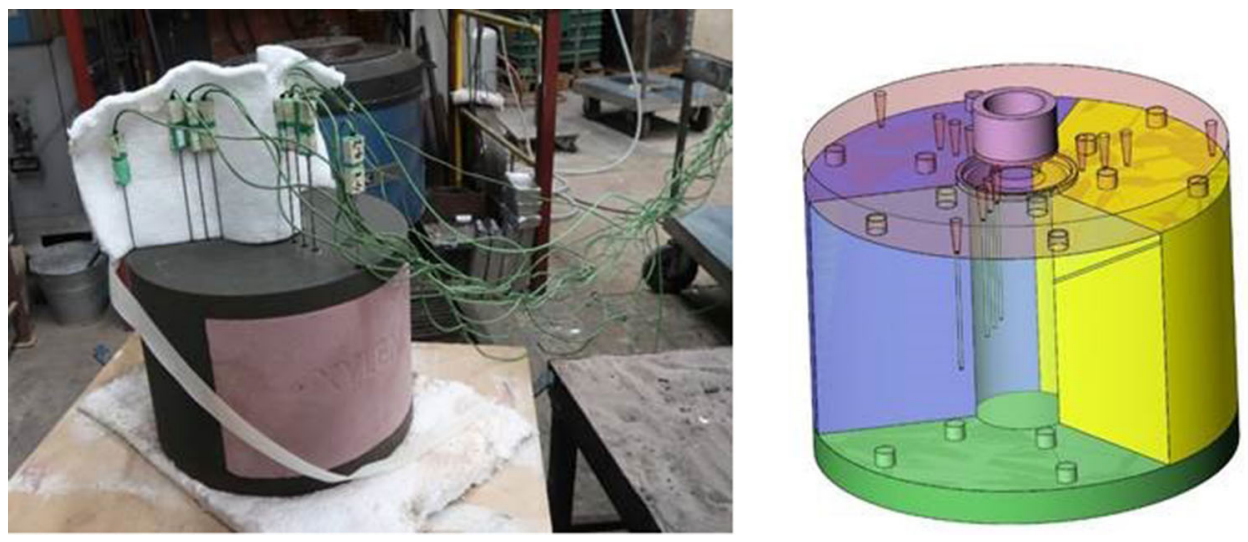

Figure 1. (a) Illustration of cake-shape mold with 3 cake slices. The cylinder in the middle is where the metal was poured. The holes in each cake slice show the placement of thermocouples. (b) Measurement set-up. 
Table 1. Summary of Casting Experiments Using Cake-shape Mold

\begin{tabular}{llllll}
\hline Casting number & Metal alloy & Casting temperature $\left({ }^{\circ} \mathrm{C}\right)$ & Sand slice1 & Sand slice2 & Sand slice 3 \\
\hline 1 & Aluminum (AC43100) & 770 & P1S & P2S & F2S \\
\hline
\end{tabular}

phenolic resole-bonded sand mold using printer from company 2 (P2S), furan-bonded sand mold using printer from company 2 (F2S). It should be noted that different parameter settings in a printer can influence the physical properties of the printed molds ${ }^{10}$.

\section{Thermal Properties Measurement}

In order to provide accurate data for simulation, thermal properties of 3D-printed sand molds using phenolic resole binder were evaluated using the different methods described below.

\section{Thermal Conductivity}

Hot wire method was used to evaluate the thermal conductivity of 3D-printed sand mold. In this method, a thin Pt wire was placed between two 3D-printed cylindrical sand molds with a diameter of $50 \mathrm{~mm}$. For a short time, a current was applied to the wire. The wire acts both as a heating element and a temperature sensor. The temperature rise $(\Delta T)$ of the wire is monitored continuously during the application of the current. The thermal conductivity $(\lambda)$ is usually measured from the slope of $\Delta T$ as a function of natural logarithm (ln) of time using Eqn. 1 where $q$ is the heat input per unit length of wire.

$\lambda=\frac{q}{4 \pi} \frac{\partial(\ln t)}{\partial \Delta T}$

Eqn. 1

The average thermal conductivities were calculated from an average of 20 measurements in each temperature. The measurement of thermal conductivity at room temperature was also carried out by Hot-Disk TPS $2500 \mathrm{~S}$ for comparison. There is a good agreement between both methods, within around 5\%.

\section{Density}

The material's thermal expansion and density as a function of temperature was conducted using dilatometer NETZSCH DIL402 DC. Cylindrical 3D-printed specimens with a $12 \mathrm{~mm}$ length and $5 \mathrm{~mm}$ diameter were used. Measurements were taken under $\mathrm{He}$ atmosphere within a temperature range of $23-1400{ }^{\circ} \mathrm{C}$, with a heating rate of $10{ }^{\circ} \mathrm{C} / \mathrm{min}$.

\section{Thermal Capacity}

Differential scanning calorimetry (DSC) analysis was used to evaluate thermal capacity of 3D-printed sand samples using Netzsch DSC 404C. The specimens were heated under Ar atmosphere with a heating rate of $10{ }^{\circ} \mathrm{C} / \mathrm{min}$ up to $1400{ }^{\circ} \mathrm{C}$. Thermogravimetric analysis (TGA) was used to evaluate the mass loss during heating using Shimadzu TGA-50. The analysis was done under air atmosphere using a heating rate of $10{ }^{\circ} \mathrm{C} / \mathrm{min}$.

\section{Results and Discussion}

\section{Measured Thermal Properties of 3D-Printed Sand with Phenolic Binder}

\section{Dilatometry}

The dilatometry curve of the sample is given in Figure 2. The material exhibits a linear thermal expansion behavior up to $250{ }^{\circ} \mathrm{C}$. After that, the expansion is not linear, and this can be due to thermoplastic behavior and decomposition of the binder up to $570{ }^{\circ} \mathrm{C}$. The sudden bend around $570{ }^{\circ} \mathrm{C}$ is the transformation from $\alpha$ to $\beta$ quartz phase in silica sand. After that, the expansion is linear. After the measurement, we realized that the sample was stuck inside the container. The pistons, keeping the sample in position, could not move freely, which is necessary when determining the thermal expansion coefficient (CTE\%). In this case the result from higher temperatures $\left(T>1000{ }^{\circ} \mathrm{C}\right)$ and cooling curve is not usable. The sample's density as a function of temperature was calculated from the

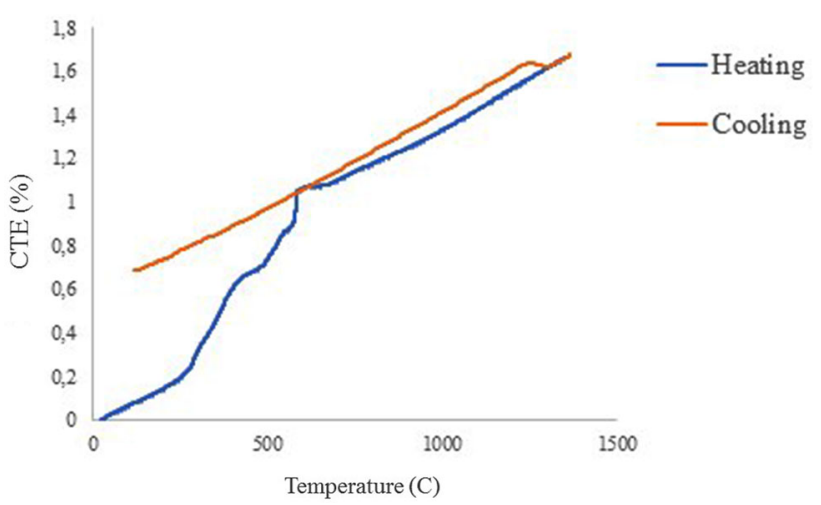

Figure 2. Thermal expansion from dilatometer analysis on phenolic-bonded 3D-printed sand mold (3DSP). 


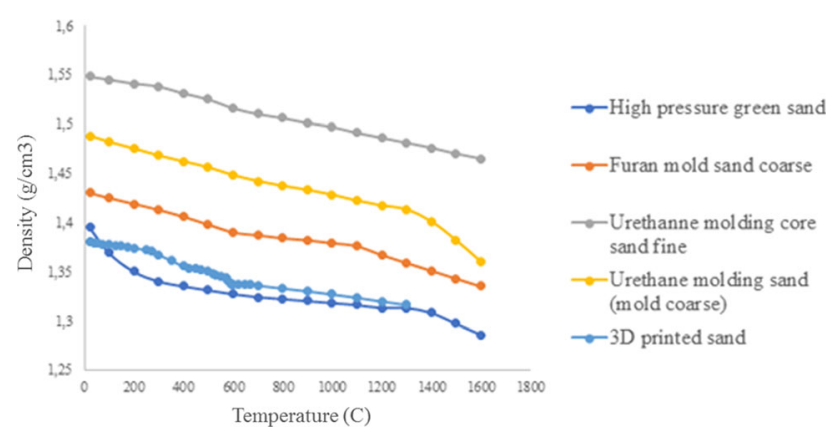

Figure 3. Calculated density of 3D-printed sand from dilatometer analysis as a function of temperature. Density as a function of temperature from other literature ${ }^{11}$ is also presented in the figure.

dilatometer measurements and is shown in Figure 3. Most of the thermal data for mold material commonly used in simulation programs is more than decades old. In addition, every foundry has their own process and specific sand that can affect the mold thermal properties. In general, it is more realistic that each foundry tests their specific molding materials for thermal properties to obtain the most accurate dataset particular to their respective operation. In this study, to establish a type of baseline to compare properties of 3DPS and traditional sand mold making, we present the thermal properties of different sand samples, including chemically bonded urethane molding sand core (fine), chemically bonded urethane molding sand mold (coarse), chemically bonded shell molding sand mold, chemically bonded furan molding sand core (fine), chemically bonded furan molding sand mold (coarse), green sand machine molded, and green sand high-pressure molding sand from literature $^{11}$ in the same figures with 3DPS-measured thermal properties. The results show that 3DPS has a lower density in comparison with most of other sand systems in foundries. When printing, the sand is placed layer by layer without compaction. This leads to a more porous structure.

\section{Differential Scanning Calorimeter (DSC)}

Specific heat capacity $\left(C_{P}\right)$ as a function of temperature was calculated from DSC analysis in a heating and cooling cycle and is shown in Figure 4. Peaks around $280{ }^{\circ} \mathrm{C}$ and at $440^{\circ} \mathrm{C}$ indicate the phenolic resin decomposition. ${ }^{12}$ The transformation of quarts takes place at $573{ }^{\circ} \mathrm{C}$, indicated by the peak of the DSC signal. The cause of the curve's appearance above $1000{ }^{\circ} \mathrm{C}$ is unknown. During cooling,

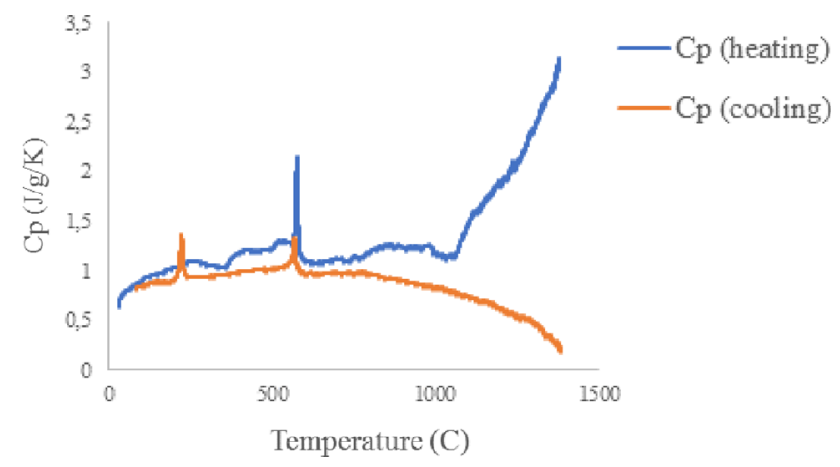

Figure 4. Specific heat capacity $(\mathrm{Cp})$ analysis on 3Dprinted sand molds in heating and cooling cycle.

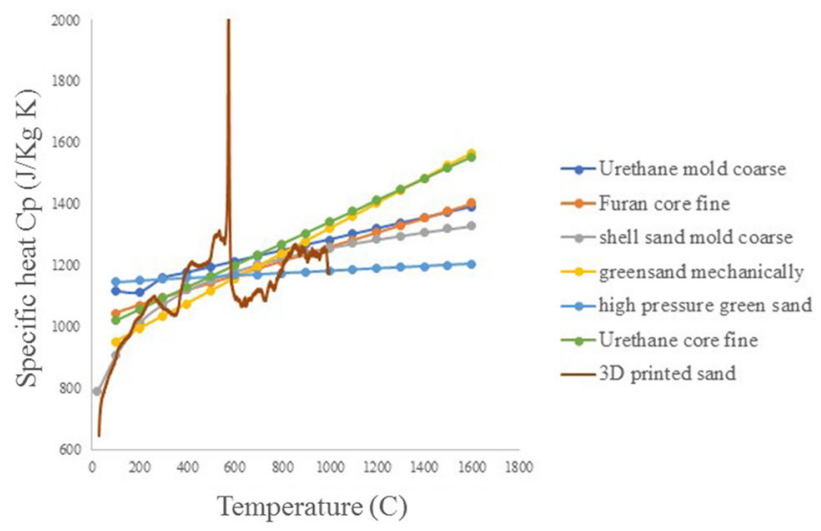

Figure 5. Specific heat capacity (Cp) of 3D-printed sand as a function of temperature. $\mathrm{Cp}$ as a function of temperature from other sources ${ }^{1}$ is also presented.

the $C p$ value is lower than the value for heating. During the heating, some parts of $\beta$-quartz convert to $\beta$-cristobalite when the sample reaches above $1050{ }^{\circ} \mathrm{C}$. During cooling, this $\beta$-cristobalite converts to $\alpha$-cristobalite at around $270{ }^{\circ} \mathrm{C}$. This phase transformation explains the peak around $270{ }^{\circ} \mathrm{C}$ in the cooling cycle. The other peak in the cooling cycle around $573{ }^{\circ} \mathrm{C}$ is the phase transformation of $\beta$ - to $\alpha$-quartz. This peak is smaller in the cooling cycle than in the heating cycle due to transformation of a part of $\beta$-quartz to $\beta$-cristobalite during heating. Figure 5 shows the measured $C p$ for different types of sand from literature. ${ }^{11}$

The results show that the specific heat capacity of 3DSP is different from values presented in the literature for different types of binders. This may be due to lower amount of 


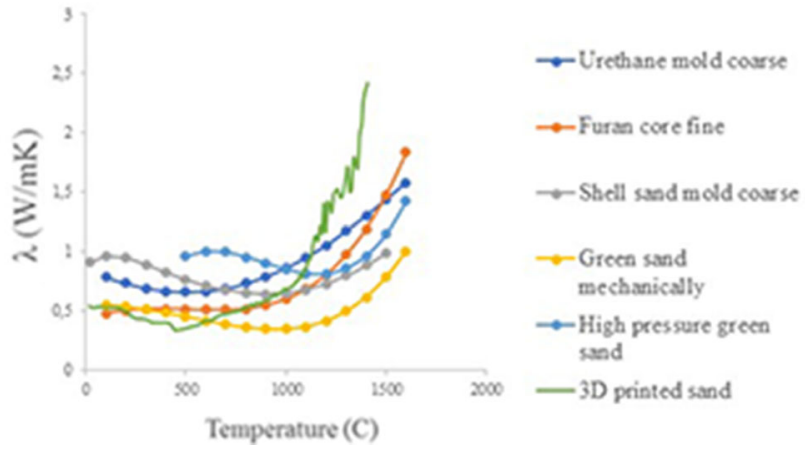

Figure 6. Thermal conductivity $(\lambda)$ of 3D-printed sand. $\lambda$ as a function of temperature from other literature ${ }^{11}$ is presented also in the figure.

binder in 3DSP and/or high purity of silica sand in these types of commercial 3D printers.

\section{Thermal Conductivity ( $\lambda)$}

Thermal conductivity of 3D-printed sand as a result of hotwire method is calculated and presented in Figure 6. $\lambda$ as a function of temperature from other papers ${ }^{11}$ is also presented in the figure. The results show that compared to most other sand molds, the $\lambda$ is lower at low temperatures $(T<500)$, and it is higher at high temperatures.

\section{Thermal Gradient Measurement and Simulation}

The aluminum alloy was cast in the cake-shape set-up, and the temperatures in certain places in the mold and middle of metal cylinder were measured during pouring and solidification. The database for aluminum ENAC43100 alloy with pouring temperature of $770{ }^{\circ} \mathrm{C}$ and the filling time for the casting of 5 seconds was used in simulation. In addition to that, the measured data for 3D-printed sand were introduced to simulation program and used to simulate the casting and cooling.

A comparison between thermal properties of sand used from database in simulation software and our measured values is shown in Figure 7.

The measured temperature in the 3 types of 3D-printed sand follows the same trend and is very close to each other. The temperature in the furan-bonded sand mold is higher than in the phenolic bonded sand molds. This is in agreement with previously reported results ${ }^{8}$ that the rate of heat absorption for furan-bonded sand is higher than phenolicbonded sand. The database from the simulation software is for conventional sand molds and cannot be used to predict the temperature gradient in the 3DSP molds (Figure 8).

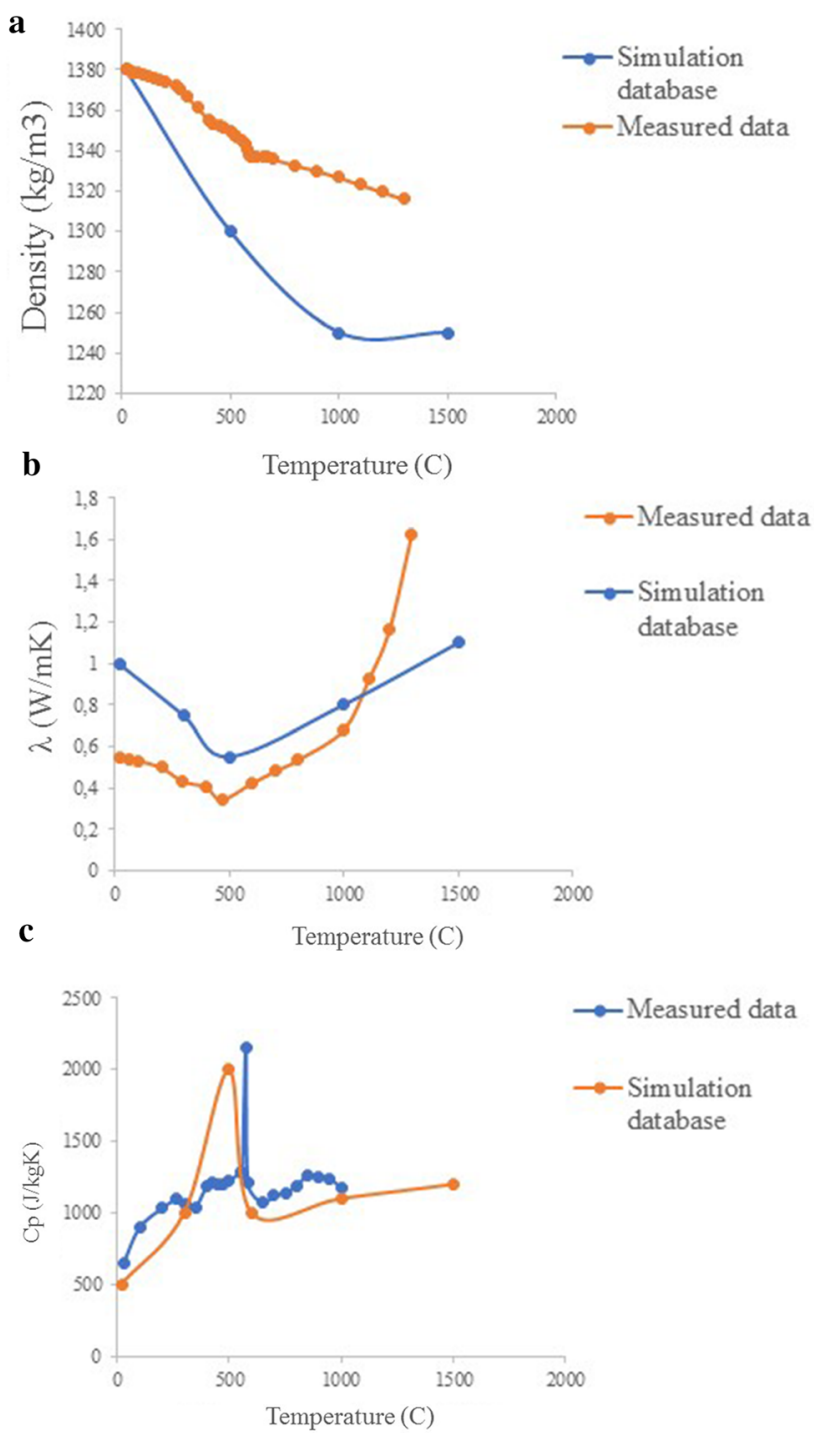

Figure 7. Thermal properties of sand used in the simulation.

\section{Conclusion}

- The measured thermal properties, such as density, specific heat capacity, and thermal diffusivity of 3D-printed sand molds as a function of temperature, are different from the published values for conventional sand binder system molds in literature.

- The conventional database for sand from software cannot predict the temperature gradient in 3D sand-printed molds. More accurate thermophysical data from 3D-printed sand molds are needed in order to simulate the heat transport in these types of sands.

- Introducing measured 3D-printed sand thermal properties in software resulted in a better prediction of heat transport and temperature in the sand. 

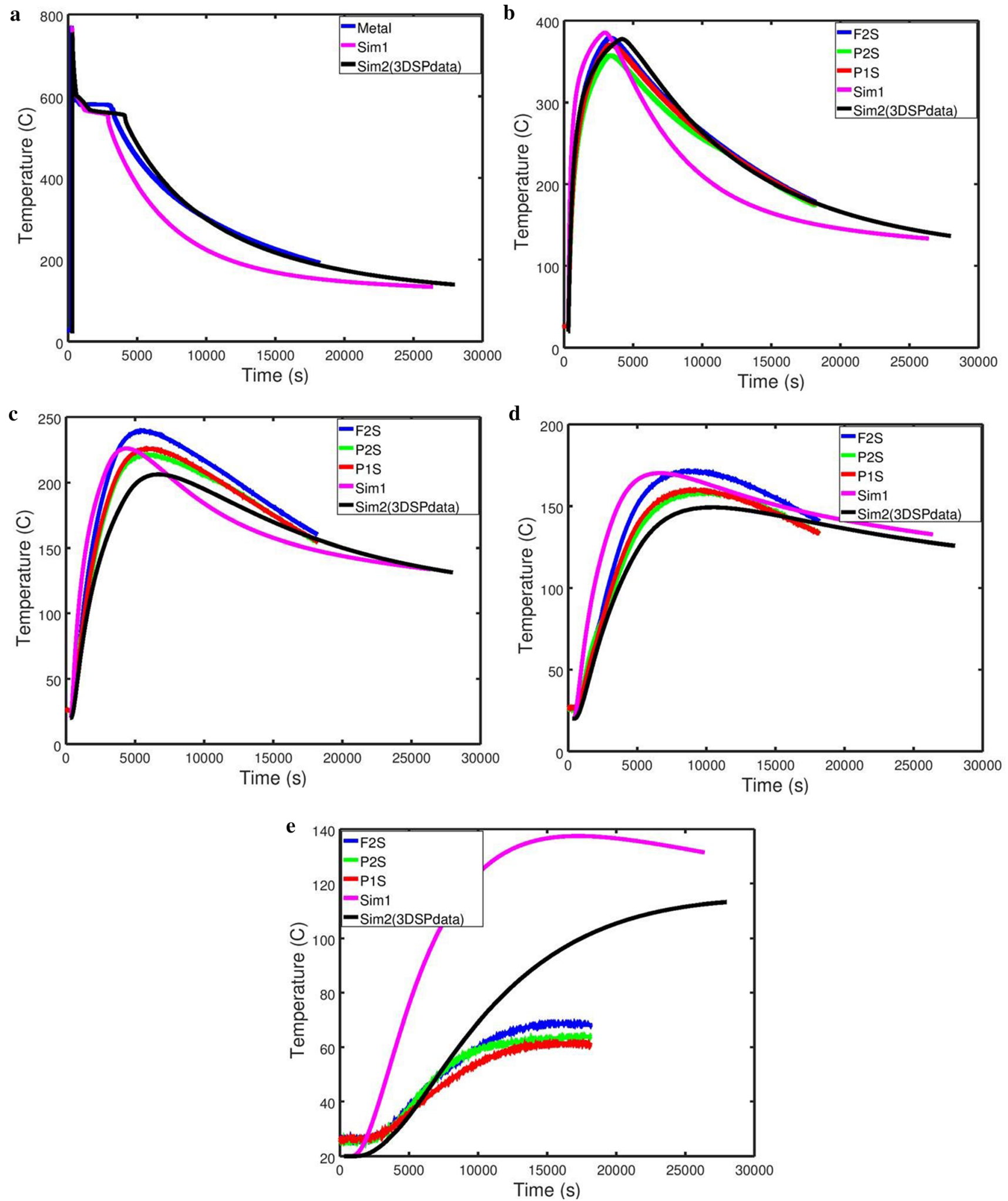

Figure 8. The measured results and simulated results using measured thermal properties of 3D-printed sand mold (Sim2) and database from simulation software (Sim1). (a) The temperature in the middle of metal, (b) measured data from 3 thermocouples in 3 different cake shapes (3 different 3DPS binder systems) with the distance of $65 \mathrm{~mm}$ from center of casting, (c) measured data with the distance of $90 \mathrm{~mm}$ from center of casting, (d) measured data with the distance of $115 \mathrm{~mm}$ from center of casting, (e) measured data with the distance of $200 \mathrm{~mm}$ from center of casting. 


\section{Acknowledgements}

The authors would like to thank the Strategic Innovation Program Metallic Materials, VINNOVA, the Swedish Energy Agency and Formas for financing part of this paper under the project Sandbox.

\section{Funding}

Open access funding provided by RISE Research Institutes of Sweden. Some parts of this paper results were financed by Metalliska Material Financing Program and VINNOVA under project Sandbox.

\section{Data Availability}

The data are available

\section{Code Availability}

Available

\section{Declarations}

Conflict of interest The authors declare that they have no conflict of interests

Open Access This article is licensed under a Creative Commons Attribution 4.0 International License, which permits use, sharing, adaptation, distribution and reproduction in any medium or format, as long as you give appropriate credit to the original author(s) and the source, provide a link to the Creative Commons licence, and indicate if changes were made. The images or other third party material in this article are included in the article's Creative Commons licence, unless indicated otherwise in a credit line to the material. If material is not included in the article's Creative Commons licence and your intended use is not permitted by statutory regulation or exceeds the permitted use, you will need to obtain permission directly from the copyright holder. To view a copy of this licence, visit http://creativecommons. org/licenses/by/4.0/.

\section{REFERENCE}

1. C. Bate, Fundamental Study on 3d Sand Printed Molds: Metal Flow and Thermal Properties, in Mechanical Engineering. The Pennsylvania State University (2019)

2. S.R. Sama, T. Badamo, G. Manogharan, Case studies on integrating 3D sand-printing technology into the production portfolio of a sand-casting foundry. Int. J. Metalcasting. 14(1), 12-24 (2020). https://doi.org/ 10.1007/s40962-019-00340-1
3. J. Wang, S.R. Sama, G. Manogharan, Re-thinking design methodology for castings: 3D sand-printing and topology optimization. Int. J. Metalcasting. 13(1), 2-17 (2019). https://doi.org/10.1007/s40962-0180229-0

4. J. Thiel, S. Ravi, N. Bryant, Advancements in materials for three-dimensional printing of molds and cores. Int. J. Metalcasting. 11(1), 3-13 (2017). https://doi.org/10.1007/s40962-016-0082-y

5. M. Łagiewka, Determination of thermophysical properties for selected molding sands. Acta. Phys. Pol. A. 136(6) (2019)

6. P.K. Krajewski, G. Piwowarski, W.K. Krajewski, Determining temperature dependencies of sand mould thermal properties. Mater. Sci. Forum. 790-791, 452-457 (2014)

7. J. Walker, E. Harris, C. Lynagh et al., 3D printed smart molds for sand casting. Int. J. Metalcasting. 12(4), 785-796 (2018). https://doi.org/10.1007/ s40962-018-0211-x

8. J. Tóth, J.T. Svidró, A. Diószegi et al., Heat absorption capacity and binder degradation characteristics of 3D printed cores investigated by inverse fourier thermal analysis. Int. J. Metalcasting. 10(3), 306-314 (2016). https://doi.org/10.1007/s40962-016-0043-5

9. D. Martinez, C. Bate, G. Manogharan, Towards functionally graded sand molds for metal casting: engineering thermo-mechanical properties using 3D sand printing. JOM 72(3), 1340-1354 (2020)

10. N. Bryant, T. Frush, J. Thiel et al., Influence of machine parameters on the physical characteristics of 3D-printed sand molds for metal casting. Int. J. Metalcasting. (2020). https://doi.org/10.1007/s40962020-00486-3

11. J.V. Shah, Bringing mold material thermophysical data up to speed: because of the ever-growing functionality of casting process modeling programs, mold material thermal input data have been evaluated and redefined. Mod. Cast. 94, 30-33 (2004)

12. J. Bouajila, G. Raffin, S. Alamercery et al., Phenolic resins (IV). Thermal degradation of crosslinked resins in controlled atmospheres. Polym. Polym. Compos. 11(5), 345-357 (2003)

Publisher's Note Springer Nature remains neutral with regard to jurisdictional claims in published maps and institutional affiliations. 